\title{
Cost-Benefit Analysis and Challenges of Implementing FSC Standards in Rubber Plantations in Southern Thailand*
}

\author{
Chaiya KONGMANEE ${ }^{1}$, Ferdoushi AHMED ${ }^{2}$, Onanong LONGPICHAI ${ }^{3}$
}

Received: September 01, 2020 Revised: October 26, 2020 Accepted: November 05, 2020

\begin{abstract}
This study examines the cost and benefit (i.e., income) of the Forest Stewardship Council (FSC) rubber plantations in Thailand. The study attempts to identify the challenges to the implementation of FSC standards in rubber plantations in the country. A total of 60 rubber farmers in two Southern provinces, namely, Songkhla and Rayong, were interviewed through a standardized questionnaire to gather primary data. The study found that small-, medium- and large-sized FSC rubber plantations were worth investing in. All sizes of rubber plantations had similar values of benefit cost ratio (BCR). It was also found that the values of the discount payback period (DPP) of the three forms of FSC rubber plantations were 9-12 years, while the large rubber plantations had the highest internal rate of return (IRR) (19.0\%). It implies that the large-size plantations had the highest values. The rubber farmers in the study area reported that they are facing a number of problems and hardships in implementing FSC standards, lacking knowledge and understanding of FSC, especially for preparing documentation. Therefore, the Thai government should take proper policy initiatives to remove all the problems and barriers in implementing FSC standards for the sustainable rubber production in the country.
\end{abstract}

Keywords: Cost Benefit Analysis, Challenges, FSC Standards, Rubber Plantation, Thailand

JEL Classification Code: Q11, Q12, Q18

\section{Introduction}

Thailand's natural rubber (NR) sector mirrors both the country's impressive growth and the limitations on that growth. Thailand is the world's largest NR producer and exporter, employing around one million families or up to six million people, and is the third largest source of

\footnotetext{
*Acknowledgements:

[1] Conflicts of Interest: The authors declare that there is no conflict of interest among them.

[2] The authors of the manuscript would like to thank the study participants who provided their time and efforts to participate in the survey.

${ }^{1}$ First Author. Lecturer, Faculty of Economics, Prince of Songkla University (PSU), Hat Yai, Songkhla, Thailand. Email: chaiya.k@psu.ac.th

${ }^{2}$ Corresponding Author. Lecturer, Faculty of Economics, Prince of Songkla University (PSU), Thailand [Postal Address: Hat Yai, Songkhla, 90112, Thailand] Email: ferdoushi.a@psu.ac.th

${ }^{3}$ Assistant Professor, Faculty of Economics, Prince of Songkla University (PSU), Hat Yai, Songkhla, Thailand. Email: onanong.l@psu.ac.th

(c) Copyright: The Author(s)

This is an Open Access article distributed under the terms of the Creative Commons Attribution Non-Commercial License (https://creativecommons.org/licenses/by-nc/4.0/) which permits unrestricted non-commercial use, distribution, and reproduction in any medium, provided the original work is properly cited.
}

export revenues (after electrical and electronics, and cars) (Suparat, 2012). Thailand's NR producers face two types of competition. One is from new rivals, especially Vietnam and India. The second is from synthetic rubber, whose price depends significantly on the cost of its petroleum base (the only products relying solely on natural rubber are aircraft and truck tires due to NR's resistance to heat build-up; auto tires are mainly concerned with abrasion resistance, which is a benefit of SR) (Rick \& George, 2013). Oktora and Firdani (2019) found that NR price, exchange rate, and China's economic slowdown significantly affect NR export to China, while Southeast Asian NR production has no significant effect. China, as the main importer of NR from Southeast Asia, has a big role in growing NR export in Southeast Asia. The rubber tree (Hevea brasiliensis) is cultivated for latex production in all tropical zones on over 10 million hectares (FAO 2010). Asia accounts for $97 \%$ of the world's natural rubber supply (Fox \& Castella 2013), and Thailand, Indonesia, and Malaysia are currently the world's largest natural rubber producers (Ratnasingam et al. 2015). The economic lifetime of rubber trees is 20-30 years (Krukanont \& Prasertsan, 2004; Jawjit et al., 2010; Chantuma et al., 2012; Petsri et al., 2013). In Thailand, from 
90,000 to 120,000 hectares of mature rubber plantations are clear-cut annually for replanting. The majority (68\%) of the plantations are in the south of the country (Chantuma et al. 2011). Duangmanee (2020) investigated a promising sustainable crop-insurance risk mitigation plan, namely, Group Risk Income Protection (GRIP) insurance, for the cultivation of Para rubber, a crop for which Southern Thailand constitutes over half of the national harvested area, but which recently experienced a shift in prices and yields, substantially affecting farmers.

The Forest Stewardship Council (FSC) is an international nonprofit, multi stakeholder organization established in 1993 that claims to promote responsible management of the world's forests. The FSC's stated mission is to "promote environmentally-appropriate, socially beneficial and economically viable management of the world's forests" (FSC, 2019). The FSC has some goals such as advancing globally responsible forest management, ensure equitable access to the benefits of FSC systems, create business value for products from FSC certified forests and strengthen the global network (FSC, 2013). Using the FSC logo supposedly signifies that the product comes from responsible sources environmentally appropriate, socially beneficial and economically viable. The FSC label is used on a wide range of timber and non-timber products from paper and furniture to medicine and jewelry (WWF, 2005) and aims to give consumers the option of supporting responsible forestry (Lang, 2006).

Rubber tree plantations play an important role in the socioeconomic development in Thailand. About $10 \%$ of the total population is involved in rubber tree plantations. However, rubber farming is still a family business in Thailand. More than $90 \%$ of rubber plantations are operated by smallholders whose farms are as modest as 0.3ha (Yamamoto, 2016). Rubber production has a strong impact on the rural economy and the alleviation of rural poverty, because producers are mainly smallholders who represent more than $85 \%$ of the total area where rubber is produced in Thailand (Chantuma et al. 2011), and some six million people are involved in rubber plantation activities (Jawjit et al., 2010). Smallholder rubber production is a viable and effective proposition for raising households and communities out of poverty, especially in Thailand (Fox \& Castella 2013). Financial survival is the instant issue for small farm owners and, thus, for nearly every rubber farmer in Thailand. The average rubber farm size in Thailand is between four and five hectares, and nearly all of these smallholders cultivate monocrop, resulting in less than \$500 net income per year per ha (Jongrungrot et al., 2014; Poungchompu et al., 2015). Rafia et al. (2019) revealed that remedies, which can offer succor in countries such as Malaysia, include waqf cash support (a form of charitable endowment under Islamic law) for farmers who encounter problems regarding income from production. Meager household incomes among rubber farmers help explain how roughly one-third of the Thai workforce is employed in agriculture, but agriculture contributes only $8-9 \%$ to national GDP (World Bank, 2017a). While USD2,000-3,000 per year income puts Thai rubber farmers well above the global poverty threshold, it does little to provide them and their families' opportunities to develop themselves and their communities.

Therefore, this study aims to examine the cost and return (i.e., income) of the FSC rubber plantations in Thailand. The study also attempts to identify the challenges to the implementation of FSC standards in rubber plantation in the country.

\section{Materials and Methods}

\subsection{Survey Design and Data Collection}

The study employed primary as well as secondary data to fulfill its objectives. To gather primary data, a survey was carried out in two-rubber project sites located in two different provinces, namely, Rayong and Songkhla in Thailand. These two sites are operating under the FSC-RAOT project. The farmers in these two sites are implementing FSC standards in rubber plantation. A total of 60 farmers (i.e., 30 farmers from each site) were selected and interviewed to collect the primary data. Purposive random sampling method was employed to select the samples. In other words, the respondents were selected randomly among the farmers who received FSC certification, employed FSC standards in rubber plantation and sold FSC certified rubber woods in the market. A structured questionnaire was used in interviewing the respondents.

On the other hand, the study collected secondary data related to rubber farm households, registered rubber farms under FSC-RAOT project, rubber planted areas, tapped area, production and distribution of rubber woods and other issues. Data were extracted from annual reports, statistical reports, journal articles, proceedings, government documents and other related documents by searching comprehensively electronic and non-electronic databases. References cited in the literature were searched and important studies were collected in full text.

\subsection{Data Analysis}

\subsubsection{Cost-Benefit Analysis}

For cost-benefit analysis, the study considered the cost and return of FSC rubber plantations in the study area. In this regard, the 25-years-old rubber tree was considered as the period of cutting down the rubber trees. Moreover, the market price of FSC rubber woods was taken into consideration. 
The cost components included fixed cost, variable cost and FSC cost. On the other hand, rubber income and FSC rubber wood income were considered in calculating benefits of rubber farming. Under the cost-benefit measurement, the following analyses were carried out:

a) Net present value (NPV): NPV is the difference between the present value of net cash flow along the age of rubber plantations and the present value of the investment by using either discount rate to adjust the cash flow occurring each time duration to be at one point at present.

The decision-making criteria for NPV are as follows:

- If the calculated NPV of the project is greater than zero (i.e., NPV $>0$ ), then the decision for the investment should be made or the project should be accepted.

- If the calculated NPV received from the project is lower than zero (i.e., NPV $<0$ ), then the decision for the investment shouldn't be made or the project should be rejected.

- If there are more than one interesting projects, then prioritizing/ranking of the projects can be made from the project with the highest NPV to the project with the lowest NPV.

b) Internal Rate of Return (IRR): IRR is the discount rate that makes the NPV $=0$. IRR is compared with $r$ in making decision about a project. In fact, $r$ is an interest rate of the project cost. In economic views, $r$ is obviously interest rate for loan payback, it shows that interest rate of project will be earned.

The decision-making criteria for IRR are as follows:

- If IRR of the project is greater than $r$ (i.e., IRR > r), then the decision for the investment should be made or the project should be accepted.

- If IRR of the project is lower than $r$ (i.e., IRR $<r$ ), then the decision for the investment shouldn't be made or the project should be rejected.

c) Benefit-cost ratio ( $\mathrm{B} / \mathrm{C}$ ratio): $\mathrm{B} / \mathrm{C}$ ratio compares all the returns received from the cash flow of the project with the amount of money invested in the project.

The decision-making criteria for $\mathrm{B} / \mathrm{C}$ ratio are as follows:

- If the calculated $\mathrm{B} / \mathrm{C}$ ratio is greater than 1 (i.e., $\mathrm{B} / \mathrm{C}$ ratio $>1$ ), then the decision for the investment should be made or the project should be accepted. The reason is that the project will receive all returns from the cash flow in the form of present value, which are higher than the amount of money invested.

- If the calculated $\mathrm{B} / \mathrm{C}$ ratio is lower than 1 (i.e., $\mathrm{B} / \mathrm{C}$ ratio $<1)$, then the decision for the investment shouldn't be made or the project should be rejected. d) Sensitivity analysis: Sensitivity analysis measures the risk of a project. It focuses on the changes in percent $(\%)$ cost or percent $(\%)$ income along the project time according to $\mathrm{B} / \mathrm{C}$ methods.

The present study conducted sensitivity analyses to see:

1) increase in cost at 5\%,10\%, and $15 \%$ by letting the return be a constant value according to the project duration and

2) decrease in income at 5\%, 10\%, and $15 \%$ by letting the cost be a constant value according to the project duration.

\section{Results and Discussions}

\subsection{Production Cost and Returns of FSC Rubber Plantations}

The analysis of production cost and returns of farmers who owned FSC rubber plantations was presented through the major factors such as net present value (NPV), benefit cost ratio (BCR), internal rate of return (IRR), and discount payback period (DPP) for considering of worthiness and feasibility of investment as details following:

\subsubsection{Structure of Production Cost}

Structure of rubber production costs will be classified into investment costs and operating cost, which can be divided into two periods: 1) rubber trees are 1-7 years old, ready for open tapping, and 2) rubber trees are 8-25 years old and have already been at open tapping. For investment costs, those will be expenses for land preparing, rubber seedlings, labor wage, maintenance, and so on, including farm assets, which depreciation, that will be calculated by the straightline method. Investment cost was showed on Figure 1. Cost for the working process composed of expenses for materials and supplies, fertilizers, chemicals, plantation maintenance, FSC (cash and non-cash), and labor wage. For this analysis, using household labor was an indirect cost and would be included in the calculation of this analysis as well. The wage of household labor was set to be equivalent with a wage of tapping labor hired by the share-tapping contracts. Benefit ratios at 50:50 means that labor wage is equivalent to $50 \%$ of benefits received from rubber plantation, and at 60:40 means that owner receives $60 \%$ of benefits and $40 \%$ will be wage for tapping labor.

\subsubsection{Structure of Returns}

Farmers had incomes from selling three types of products.

1) Incomes from latex, which can be processed into raw rubber sheets, cup lumps, or fresh latex will be assigned as follows: 
- dried rubber content of raw rubber sheet equals to raw rubber sheet weight $\mathrm{x} 95 \%$

- dried rubber content of fresh latex equals to fresh latex weight $\mathrm{x}$ average $\% \mathrm{DRC}$

- dried rubber content of cup lump equals to cup lump weight $\mathrm{x} 45 \%$

- That means income $=$ dried rubber content $x$ average local price in 2017 of that product

- for the price of cup lump, use an average price of the local market of cup lump for $100 \%$

2) Incomes from rubber scraps or rubber crumbs collected from asking for the average income/month that farmers could sell.

3) Incomes from 25-year-old rubber woods collected from asking for the market price and price agreement for rubber wood (if available). The analysis of the discount rate of project finance at $7.0 \%$ for 25 years.

\subsection{Expense for Managing FSC}

Results of analysis for the expense of managing FSC are showed in Figure 1. The analysis indicated that the big plantation, the medium plantation, and the small plantation had expenses at 137.14 baht (lowest), 245.33 baht, and 576.37 baht, respectively. The difference of expenses depends on the size of plantation requesting FSC certification. The major factors are expenses of financial opportunity loss, transportation, documents, and plantation management related to practicing FSC requirements. All expenses do not include expenses for FSC company promotion, which will be the response to the expenses of certification preparing, certifying, managing, and consulting. This analysis used only FSC expenses paid by farmers.

\subsubsection{Results of Analysis of Cost and Returns of FSC Rubber Plantations}

Results of analysis of cost and returns of FSC rubber plantations are showed in Table 1 as detail following.

\section{(1) Small rubber plantation}

Results of analysis for the project finance of FSC small rubber plantations indicated that NPV was equal to $30,774.85$ baht, with the value of $>0, \mathrm{BCR}$, was equal to 1.40 , with the value of $>1.0$, IRR was equal to $10.0 \%$, which was higher than the discount rate equal to $7.0 \% / y e a r$, and DPP was equal to 10.18 years. From this analysis, the study found that managing FSC small rubber plantations was worth the investment.

\section{(2) Medium rubber plantations}

Results of analysis for the project finance of FSC medium rubber plantations indicated that NPV was equal to $20,309.16$ baht, with the value of $>0, \mathrm{BCR}$, was equal to 1.32 , with the value of $>1.0$, IRR was equal to $8.0 \%$, which was higher than the discount rate equal to $7.0 \% /$ year, and DPP was equal to 12.01 years. From this analysis, the study found that managing FSC medium rubber plantations was worth the investment.

\section{(3) Large rubber plantations}

Results of analysis for the project finance of FSC large rubber plantations indicated that NPV was equal to $28,429.93$ baht, with the value of $>0, \mathrm{BCR}$, was equal to 1.44 , with the value of $>1.0$, IRR was equal to $11.0 \%$, which was higher than the discount rate equal to $7.0 \% /$ year, and DPP was equal to 9.51 years. From this analysis, the study found that managing FSC large rubber plantations was worth the investment.

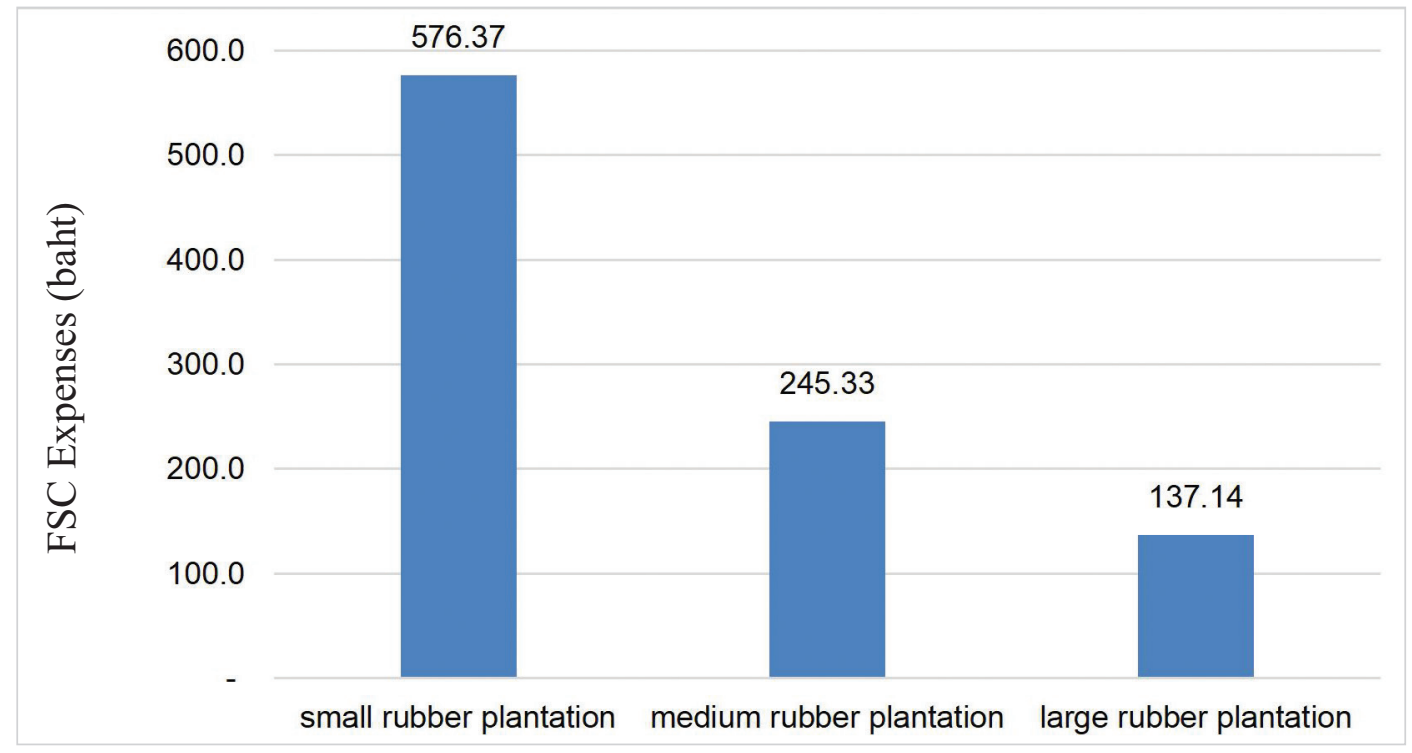

Figure 1: FSC expenses paid by farmers 
From Table 1, the study found that FSC small rubber plantations, FSC medium rubber plantations, and FSC large rubber plantations were worth the investment. FSC small rubber plantations were most valuable, and the rest had lower values. All sizes of FSC rubber plantations had similar values of BCR. Considering IRR, the study found that FSC large rubber plantations had IRR equal to $19.0 \%$, the highest of the three FSC rubber plantations, while values of DPP of the three FSC rubber plantations were at 9-12 years.

\subsubsection{Results of Analysis of Cost and Returns of FSC Rubber Plantations with Changing of The Discount Rate}

Results of analysis for the project finance of the three FSC rubber plantations by discount rates at $8 \%, 10 \%$, and $12 \%$ as shown in Table 2, the study found that all three FSC rubber plantations had NPV $>0$ for every discount rate. FSC small rubber plantations had the highest value of NPV of the three FSC rubber plantations for every discount rate. Considering the values of $\mathrm{BCR}$, the study found that all FSC rubber plantations had values of $\mathrm{BCR}>1$. This means that there will be worth investing in because returns are higher than the cost of investment. For every discount rate, the study found that FSC large rubber plantations had the highest values of the three FSC rubber plantations. At the discount rate $8 \%$, the study found that FSC large rubber plantations and FSC small rubber plantations had IRR higher than the discount rate at $8 \%$. However, there was an exception for FSC medium rubber plantations with discount rates at $10 \%$ and $12 \%$, the study indicated that all FSC rubber plantations had IRR $<$ discount rate. This means that, when IRR is lower than the discount rate, there will be a contribution to having longer years of DPP for the investment.

Table 1: Results of analysis for the project finance of FSC rubber plantations

\begin{tabular}{|l|c|c|c|}
\hline Indicators & Small Rubber Plantation & Medium Rubber Plantation & Large Rubber Plantation \\
\hline NPV (baht) & $30,774.85$ & $20,309.16$ & $28,429.93$ \\
\hline BCR & 1.40 & 1.32 & 1.44 \\
\hline IRR (\%) & 10.0 & 8.0 & 11.0 \\
\hline DPP (year) & 10.18 & 12.01 & 9.51 \\
\hline
\end{tabular}

Table 2: Results of analysis of project finance with changing of the discount rate

\begin{tabular}{|l|c|c|c|c|}
\hline Indicators & $\begin{array}{c}\text { Discount rate } \\
\text { (\%) }\end{array}$ & $\begin{array}{c}\text { Small rubber } \\
\text { plantation }\end{array}$ & $\begin{array}{c}\text { Medium rubber } \\
\text { plantation }\end{array}$ & $\begin{array}{c}\text { Large rubber } \\
\text { plantation }\end{array}$ \\
\hline \multirow{3}{*}{ NPV (baht) } & 8 & $24,580.74$ & $15,759.07$ & $22,867.88$ \\
\cline { 2 - 5 } & 10 & $15,381.05$ & $9,108.19$ & $14,619.34$ \\
\hline \multirow{3}{*}{ BCR } & 12 & $9,162.02$ & $4,715.16$ & $9,050.27$ \\
\cline { 2 - 5 } & 8 & 1.36 & 1.28 & 1.40 \\
\cline { 2 - 5 } & 10 & 1.28 & 1.20 & 1.32 \\
\hline \multirow{3}{*}{ IRR (\%) } & 12 & 1.21 & 1.13 & 1.25 \\
\cline { 2 - 5 } & 10 & 9.0 & 7.0 & 10.0 \\
\cline { 2 - 5 } & 8 & 7.0 & 5.0 & 8.0 \\
\hline \multirow{3}{*}{ DPP (year) } & 10 & 5.0 & 3.0 & 6.0 \\
\cline { 2 - 5 } & 12 & 10.52 & 12.60 & 9.78 \\
\cline { 2 - 5 } & & 11.48 & 14.34 & 10.58 \\
\hline
\end{tabular}




\subsubsection{Results of Analysis of Cost Sensitivity and Returns of FSC Rubber Plantations}

The analysis of financial sensitivity assigning the discount rate at $7 \%$ was classified into three scenarios:

\section{Scenario 1: Increase and decrease in all incomes}

By assigning all incomes selling dried rubber products and rubber woods to be increased by $5 \%, 10 \%$, and $15 \%$ as the results of the analysis in Table 3, the study found that all FSC rubber plantations had NPV $>0$. The FSC small rubber plantations had the most increase of NPV from 36,203.46 baht to $47,060.69$ baht, with the lower incomes of FSC large rubber plantations that had an increase of NPV from 33,105.98 baht to $42,458.09$ baht, and FSC medium rubber plantations had an increase of NPV from 24,532.02 baht to 32,977.74 baht. These also contributed for the most increase of BCR of the FSC large rubber plantations, from 1.51 to 1.65 or $9.2 \%$, with the lower BCR of FSC small rubber plantations from 1.47 to 1.60 or $8.8 \%$, and the least BCR of FSC medium rubber plantations from 1.38 to 1.51 or $9.4 \%$. Also, the study indicated that IIR values of all FSC rubber plantations were higher than the discount rate at $7.0 \%$. This means that FSC large rubber plantations are the most valuable of the three FSC rubber plantations.

By assigning all incomes selling dried rubber products and rubber woods to be decreased by $5 \%, 10 \%$, and $15 \%$ as the results of the analysis in Table 3 , the study found that all FSC rubber plantations had NPV $>0$. The FSC small rubber plantations had the most decrease of NPV, from 25,346.24 baht to $14,489.01$ baht, with the lower incomes of the FSC large rubber plantations that had a decrease of NPV from $23,753.88$ baht to $14,401.17$ baht, and FSC medium rubber plantations had a decrease of NPV from 16,086.30 baht to 7,640.58 baht. All FSC rubber plantations had a decrease of all BCR values. BCR of FSC large rubber plantations decreases from 1.36 to 1.22 or $10.3 \%$, with the lower BCR of FSC small rubber plantations from 1.33 to 1.19 or $10.5 \%$, and FSC medium rubber plantations had the least decreasing BCR from 1.25 to 1.12 or $10.4 \%$. By decreasing incomes at $15 \%$, the study indicated that all FSC rubber plantations had IIR values lower than the discount rate at $7.0 \%$ as in Table 3 .

\section{Scenario 2: Increase and decrease in all costs}

By assigning all costs to be increased by $5 \%, 10 \%$, and $10 \%$ as the results of the analysis in Table 4, the study found that all FSC rubber plantations had NPV $>0$. FSC small rubber plantations had a decrease of NPV from 26,884.98 baht to $19,105.24$ baht, with the lower NPV of FSC large rubber plantations that had a decrease of NPV from $25,175.37$ baht to $18,666.26$ baht, and FSC medium rubber plantations had a decrease of NPV from 17,101.70 baht to $10,686.77$ baht. This contributed to decreasing of BCR of FSC large rubber plantations from 1.37 to 1.25 or $8.7 \%$, with the lower $\mathrm{BCR}$ of FSC small rubber plantations from 1.33 to 1.21 or $9.0 \%$, and the least BCR of FSC small rubber plantations from 1.25 to 1.14 or $8.8 \%$ as Table 4 .

Table 3: Results of analysis of the sensitivity of project finance for the case of increasing and decreasing of all incomes at $5 \%, 10 \%$, and $15 \%$

\begin{tabular}{|c|c|c|c|c|}
\hline Income & Indicator & $\begin{array}{l}\text { Small rubber } \\
\text { plantation }\end{array}$ & $\begin{array}{l}\text { Medium rubber } \\
\text { plantation }\end{array}$ & $\begin{array}{l}\text { Large rubber } \\
\text { plantation }\end{array}$ \\
\hline Increase at $5 \%$ & $\begin{array}{c}\text { NPV ((baht) } \\
\text { BCR } \\
\text { IRR }(\%)\end{array}$ & $\begin{array}{c}36,203.46 \\
1.47 \\
11.0 \\
\end{array}$ & $\begin{array}{c}24,532.02 \\
1.38 \\
10.0 \\
\end{array}$ & $\begin{array}{c}33,105.98 \\
1.51 \\
13.0\end{array}$ \\
\hline Increase at $10 \%$ & $\begin{array}{c}\text { NPV ((baht) } \\
\text { BCR } \\
\text { IRR }(\%)\end{array}$ & $\begin{array}{c}41,632.07 \\
1.54 \\
13.0\end{array}$ & $\begin{array}{c}28,704.88 \\
1.45 \\
11.0\end{array}$ & $\begin{array}{c}37,782.04 \\
1.58 \\
14.0\end{array}$ \\
\hline Increase at $15 \%$ & $\begin{array}{c}\text { NPV ((baht) } \\
\text { BCR } \\
\text { IRR }(\%)\end{array}$ & $\begin{array}{c}47,060.69 \\
1.60 \\
14.0\end{array}$ & $\begin{array}{c}32,977.74 \\
1.25 \\
7.0\end{array}$ & $\begin{array}{c}42,458.09 \\
1.65 \\
15.0\end{array}$ \\
\hline Decrease at $5 \%$ & $\begin{array}{c}\text { NPV ((baht) } \\
\text { BCR } \\
\text { IRR }(\%)\end{array}$ & $\begin{array}{c}25,346.24 \\
1.33 \\
9.0\end{array}$ & $\begin{array}{c}16,086.30 \\
1.25 \\
7.0\end{array}$ & $\begin{array}{c}23,753.88 \\
1.36 \\
10.0\end{array}$ \\
\hline Decrease at $10 \%$ & $\begin{array}{c}\text { NPV ((baht) } \\
\text { BCR } \\
\operatorname{IRR~}(\%)\end{array}$ & $\begin{array}{c}19,917.62 \\
1.26 \\
7.0\end{array}$ & $\begin{array}{c}1,863.44 \\
1.18 \\
5.0\end{array}$ & $\begin{array}{c}19,077.82 \\
1.29 \\
8.0\end{array}$ \\
\hline Decrease at $15 \%$ & $\begin{array}{c}\text { NPV ((baht) } \\
\text { BCR } \\
\text { IRR }(\%)\end{array}$ & $\begin{array}{c}14,489.01 \\
1.19 \\
5.0\end{array}$ & $\begin{array}{c}7,640.58 \\
1.12 \\
3.0\end{array}$ & $\begin{array}{c}14,401.17 \\
1.22 \\
6.0\end{array}$ \\
\hline
\end{tabular}


Chaiya KONGMANEE, Ferdoushi AHMED, Onanong LONGPICHAI /

Table 4: Results of analysis of the sensitivity of project finance for the case of increasing and decreasing of all costs at $5 \%$, $10 \%$, and $15 \%$

\begin{tabular}{|c|c|c|c|c|}
\hline Cost & Indicator & $\begin{array}{c}\text { Small rubber } \\
\text { plantation }\end{array}$ & $\begin{array}{l}\text { Medium rubber } \\
\text { plantation }\end{array}$ & $\begin{array}{l}\text { Large rubber } \\
\text { plantation }\end{array}$ \\
\hline Increase at $5 \%$ & $\begin{array}{c}\text { NPV ((baht) } \\
\text { BCR } \\
\text { IRR (\%) }\end{array}$ & $\begin{array}{c}26,884.98 \\
1.33 \\
9.0 \\
\end{array}$ & $\begin{array}{c}17.101 .70 \\
1.25 \\
7.0 \\
\end{array}$ & $\begin{array}{c}25,175.37 \\
1.37 \\
10.0 \\
\end{array}$ \\
\hline Increase at $10 \%$ & $\begin{array}{c}\text { NPV ((baht) } \\
\text { BCR } \\
\text { IRR }(\%)\end{array}$ & $\begin{array}{c}22,995.11 \\
1.27 \\
7.0\end{array}$ & $\begin{array}{c}13,894.24 \\
1.20 \\
5.0\end{array}$ & $\begin{array}{c}21,920.82 \\
1.31 \\
8.0\end{array}$ \\
\hline Increase at $15 \%$ & $\begin{array}{c}\text { NPV ((baht) } \\
\text { BCR } \\
\text { IRR }(\%)\end{array}$ & $\begin{array}{c}19,105.24 \\
1.21 \\
6.0\end{array}$ & $\begin{array}{c}10,686.77 \\
1.14 \\
7.0\end{array}$ & $\begin{array}{c}18,666.26 \\
1.25 \\
7.0\end{array}$ \\
\hline Decrease at $5 \%$ & $\begin{array}{c}\text { NPV ((baht) } \\
\text { BCR } \\
\text { IRR }(\%)\end{array}$ & $\begin{array}{c}34,664.72 \\
1.47 \\
12.0\end{array}$ & $\begin{array}{c}23,516.62 \\
1.39 \\
10.0\end{array}$ & $\begin{array}{c}31,684.49 \\
1.51 \\
13.0\end{array}$ \\
\hline Decrease at $10 \%$ & $\begin{array}{c}\text { NPV ((baht) } \\
\text { BCR } \\
\text { IRR }(\%)\end{array}$ & $\begin{array}{c}38,554.59 \\
1.55 \\
13.0\end{array}$ & $\begin{array}{c}26,724.09 \\
1.46 \\
11.0\end{array}$ & $\begin{array}{c}34,939.04 \\
1.60 \\
14.0\end{array}$ \\
\hline Decrease at $15 \%$ & $\begin{array}{c}\text { NPV ((baht) } \\
\text { BCR } \\
\text { IRR }(\%)\end{array}$ & $\begin{array}{c}2,444.46 \\
1.64 \\
14.0\end{array}$ & $\begin{array}{c}29,931.55 \\
1.55 \\
13.0\end{array}$ & $\begin{array}{c}38,193.60 \\
1.69 \\
16.0\end{array}$ \\
\hline
\end{tabular}

By assigning all costs to be decreased by $5 \%, 10 \%$, and $10 \%$ as the results of the analysis in Table 4 , the study found that all FSC rubber plantations had NPV $>0$. FSC small rubber plantations had the most increase of NPV, from 34,664.72 baht to $42,444.46$ baht, with the lower NPV of FSC large rubber plantations that had an increase of NPV from 31,684.49 baht to $38,193.60$ baht, and FSC medium rubber plantations had an increase of NPV from 23,516.62 baht to 29,931.55 baht. This contributed to an increase of BCR of FSC large rubber plantations from 1.51 to 1.69 or $11.9 \%$, with the lower BCR of FSC small rubber plantations from 1.47 to 1.64 or $11.5 \%$, and the least BCR of FSC small rubber plantations from 1.39 to 1.55 or $11.5 \%$. Also, the study indicated that the IIR values of all FSC rubber plantations were higher than the discount rate at $7.0 \%$. This means that FSC large rubber plantations are the most valuable of the three FSC rubber plantations.

\section{Scenario 3: More incomes received from FSC rubber} woods

From the above results, the study found that all samples of the studied group sold rubber woods by the market price without receiving any top-up price. Then by assigning incomes of selling FSC rubber woods to be increased by $5 \%, 10 \%$, and $15 \%$, the study showed the results of analysis in Table 7 that all FSC rubber plantations had NPV $>0$. Increasing price of FSC rubber woods, the study found, caused a small effect on values of NPV. FSC small rubber plantations had the most increase of NPV, from 31,301.87 baht to 32,355.92 baht, with the lower NPV of FSC large rubber plantations from $28,946.52$ baht to $29,979.69$ baht, and the least NPV of FSC medium rubber plantations from 20,825.75 baht to $21,858.92$ baht. The price of FSC rubber woods contributed to the most increase of BCR of the FSC large rubber plantations, from 1.44 to 1.46 , with the lower BCR of FSC small rubber plantations, from 1.40 to 1.42, and the least BCR of FSC medium rubber plantations from 1.32 to 1.34. All FSC rubber plantations had no IIR values changed, and those were still higher than the discount rate at $7.0 \%$.

\subsection{Challenges to Implementation of FSC Standards in Rubber Plantation and Recommendations}

The Rubber Authority of Thailand (RAOT) is the major working unit to support and promote the principle of sustainable forest management by assigning FSC requirements to be one part of regulations for receiving rubber replanting aid fund (RRAF). The reason is that most rubber plantations will receive RRAF from RAOT. Then, quickly expanding FSC rubber plantations is possible with the cooperation of RAOT by enclosing FSC requirements as part of regulations for farmers requesting for RRAF 
Table 5: Results of analysis of the sensitivity of project finance for the case of increasing of all incomes of FSC rubber woods at $5 \%, 10 \%$, and $15 \%$

\begin{tabular}{|c|c|c|c|c|}
\hline Income & Indicator & $\begin{array}{c}\text { Small rubber } \\
\text { plantation }\end{array}$ & $\begin{array}{l}\text { Medium rubber } \\
\text { plantation }\end{array}$ & $\begin{array}{c}\text { Large rubber } \\
\text { plantation }\end{array}$ \\
\hline \multirow{3}{*}{$\begin{array}{l}\text { Increase income of } \\
\text { FSC rubber woods } \\
\text { at } 5 \%\end{array}$} & NPV (baht) & $31,301.87$ & $20,825.75$ & $28,946.52$ \\
\hline & $\mathrm{BCR}$ & 1.40 & 1.32 & 1.44 \\
\hline & IRR (\%) & 10.0 & 8.0 & 11.0 \\
\hline \multirow{3}{*}{$\begin{array}{l}\text { Increase income of } \\
\text { FSC rubber woods } \\
\text { at } 10 \%\end{array}$} & NPV (baht) & $31,828.89$ & $21,342.33$ & $29,463.10$ \\
\hline & $\mathrm{BCR}$ & 1.41 & 1.33 & 1.45 \\
\hline & IRR (\%) & 10.0 & 8.0 & 11.0 \\
\hline \multirow{3}{*}{$\begin{array}{l}\text { Increase income of } \\
\text { FSC rubber woods } \\
\text { at } 15 \%\end{array}$} & NPV (baht) & $32,355.92$ & $21,858.92$ & $29,979.69$ \\
\hline & $\mathrm{BCR}$ & 1.42 & 1.34 & 1.46 \\
\hline & IRR (\%) & 10.0 & 8.0 & 11.0 \\
\hline
\end{tabular}

Reducing expenses related to FSC certification and complications in preparing stages of certification by the indepth interviews of key informants, the study found that the certification process caused some transaction costs with the observation that the concerned persons had designed many unnecessary activities that would be an indirect cost and implicit cost. These costs will be different depending on location circumstances and business targets of companies promoting FSC. This analysis of cost and returns did not include those costs. Then, the relevant working units should consider reducing indirect costs and implicit costs occurring in the stages of preparing and evaluating.

For measurements of seeking business benefits from being consultants of managing FSC rubber plantations by the in-depth interviews, the study found that the stage of preparing requests for FSC certification had the feature of rent-seeking from being a consultant of the concerned person and practicing unfair pricing of rubber woods (mentioned below). This will be an indirect cost paid by the companies promoting FSC. Consultants have delayed the time of certification and did not provide complete information for the reason that consultants will gain the highest benefits of being consultants. Then, the concerned working units should set the consulting system to work with public consultants by dealing with consultants from the educational institutions or government working units. The consulting system must have clarity and will be used when only with necessary.

Supporting the fair price of FSC rubber woods in future contracts, the study found that every farmer sold FSC rubber woods by the market price without receiving any top-up price. Companies promoting FSC did not show the price of FSC rubber woods that was supposed to be higher than the market price. Nevertheless, the processed FSC rubber woods have a higher added value 3-10 times the regular rubber woods. This reflects that companies promoting FSC feature rent-seeking from producing FSC rubber woods by the market price, but selling FSC rubber woods at a higher price in the downstream markets. These benefits are not fairly distributed to farmers. Then, the relevant working units should come in and look at the FSC rubber wood sale contract and should enforce the regulation of selling FSC rubber wood that will lead to benefit sharing at a fair price among the concerned persons.

For providing knowledge and training for farmers, the study found that most farmers received training only once before preparing for FSC certification. Providing more training will promote the expansion of more FSC rubber plantations.

The extension and FSC support should take place through group such as RAOT cooperative given that most farmers growing rubber are RAOT cooperative member and farmer group member.

A Thai FSC database that farmers are able to access should be designed and developed, including complete information and transparency, such as number of certificates and number of FSC-certified farmers.

\section{Conclusion}

The present study conducted a cost-benefit analysis to assess various costs and benefits (i.e., income) of the FSC rubber plantations in Thailand. The study also focused on the challenges that the rubber farmers face in implementing FSC standards in rubber plantation. The findings revealed that all three sizes of FSC rubber plantations (i.e., small, medium and large size) were worth investments. Similarly, all sizes of FSC rubber plantations had similar values of BCR. The values of DPP of the three different sizes of FSC rubber plantations were estimated to be 9-12 years. However, considering IRR, the study found that FSC large rubber plantations had the 
highest IRR (19.0\%). The findings indicate that, among the three different forms of FSC rubber plantations, the largesize plantations were most valuable. The study also found that the rubber farmers are facing a number of challenges in implementing FSC standards, especially for preparing documentation, and lacking knowledge and understanding of FSC. Therefore, the Thai government should take proper policy initiatives to remove all the problems and barriers in implementing FSC standards for the sustainable rubber production in the country.

\section{References}

Chantuma, A., Kunarasiri, A., \& Chantuma, P. (2012). Rubber new planting in Thailand: Towards the world affected climate change. Rubber Thai Journal, 1, 10-47

Chantuma, P., Lacote, R., Leconte, A., \& Gohet, E. (2011). An innovative tapping system, the double cut alternative, to improve the yield of Hevea brasiliensis in Thai rubber plantations. Field Crop. Research, 121, 416-422.

Duangmanee, K. (2020). Feasibility of Group Risk Income Protection Insurance for Para Rubber in Thailand. Journal of Asian Finance, Economics and Business, 7(10), 621-628. https://doi.org/10.13106/jafeb.2020.vol7.no10.621

FAO. (2010). Global forest resources assessment. FAO Forestry Paper. 163, 329. Available at: http://www.fao.org/3/a-i1757e. pdf (accessed on 20 June 2019).

Fox, J., \& Castella, J. C. (2013). Expansion of rubber (Hevea brasiliensis) in mainland Southeast Asia: What are the prospects for smallholders? Journal of Peasant Studies, 40, 155-170.

FSC. (2019). Mission and Vision - Protecting forests for future generations. Retrieved from http://us.fsc.org.

FSC. (2013). FSC Forest Stewardship Council® - Global Strategy. Retrieved from http://Ic.fsc.org.

Jawjit, W., Kroeze, C., \& Rattanapan, S. (2010). Greenhouse gas emissions from rubber industry in Thailand. Journal of Cleaner Production, 18, 403-411.

Jongrungrot, V., Thungwa, S., \& Snoeck, D. (2014). Tree-crop diversification in rubber plantations to diversify sources of income for small-scale rubber farmers in Southern Thailand. Bois et Forests des Tropiques, 321(3), 21-32.
Krukanont, P., \& Prasertsan, S. (2004). Geographical distribution of biomass and potential sites of rubber wood fired power plants in Southern Thailand. Biomass Bioenerg, 26, 47-59.

Oktora, S. I., \& Firdani, A. M. (2019). Natural Rubber Economics between China and Southeast Asia: The Impact of China's Economic Slowdown. Journal of Asian Finance, Economics and Business, 6(2), 55-62. https://doi.org/10.13106/jafeb.2019. vol6.no2.55

Petsri, S., Chidthaisong, A., Pumijumnong, N., \& Wachirnat, C. (2013). Greenhouse gas emissions and carbon stock changes in rubber tree plantations in Thailand from 1990-2004. Journal of Cleaner Production, 52, 61-70.

Poungchompu, S. \& Chantanop, S. (2015). Factor affecting technical efficiency of smallholder rubber farming in northeast Thailand. American Journal of Agricultural and Biological Sciences, 10(2), 83-90. DOI: 10.3844/ajabssp.2015.83.90

Rafia, A., Muhibbullah, M., \& Morshed, N. (2019). Factors affecting the intention of the rice farmers to adopt the integrated cash waqf environmental protection model: an empirical study in Kedah Malaysia. Journal of Asian Finance, Economics and Business, 6(4), 189-199. https://doi.org/10.13106/jafeb.2019. vol6.no4.189

Ratnasingam, J., Ramasamy, G., Wai, L. T., Senin, A. L., \& Muttiah, N. (2015). The prospects of rubberwood biomass energy production in Malaysia. Bio Resources, 10, 2526-2548.

Rick, D., \& George, A. (2013). Upgrading Thailand's Rubber Industry: Opportunities and Challenges. Thammasat Economic Journal, 31(4), 43-66.

Suparat, S. (2012). Thai Automotive Industry. Presentation to IRTEC Conference 2012, Kuala Lumpur, Oct. 12-12,

World Bank. (2017a). World development indicators. Washington, DC, USA: World Bank. Retrieved July 14, 2017 from http://data.worldbank.org/data-catalog/world-developmentindicators.

WWF. (2005). The effects of FSC Certification in Estonia, Germany, Latvia, Russia, Sweden and the UK. WWF (2005). Panda.org. Retrieved 15 January 2013.

Yamamoto, H. (Ed.) (2016). Research for consideration of a policy proposal to reform the natural rubber industry's structure and stabilize farmers' dealing conditions in Thailand. ERIA Research Project FY2015, No. 12. 